\title{
ODRŽIVOST KORIŠĆENJA OKLASKA KUKURUZA KAO GORIVA U MALIM GENERATORIMA TOPLOTE
}

\section{SUSTAINABILITY OF CORN COB USE AS A FUEL IN SMALL HEAT GENERATORS}

\author{
Aleksandar Nesterović, Đorđe Đatkov, Miodrag Višković, Fakultet tehničkih nauka, Novi Sad
}

\section{Oblast - ČISTE ENERGETSKE TEHNOLOGIJE}

Kratak sadržaj - U ovom radu su prikazani rezultati istraživanja održivosti korišćenja oklaska kukuruza kao goriva u malim generatorima toplote.

Ključne reči: oklasak kukuruza, gorivo, mali generatori toplote, održivost

\begin{abstract}
In this paper are presented the results of sustainability assessment of corn cob as a fuel in small heat appliances.
\end{abstract}

Keywords: corn cob, fuel, small heat generators, sustainability

\section{UVOD}

Biomasa ima najveći potencijal obnovljivih izvora energije - OIE u Republici Srbiji. Prema nacionalnom akcionom planu za korišćenje obnovljivih izvora energije Republike Srbije raspoloživi tehnički potencijal biomase je oko 3,4 Mtoe (Million Tonnes of Oil Equivalent) godišnje, od čega je 2,3 Mtoe neiskorišćeni potencijal [1].

Poljoprivredna biomasa ima značajan potencijal OIE u Srbiji, a najznačajniji u AP Vojvodini [2]. Pod pojmom poljoprivredna biomasa podrazumeva se više materijala, a najznačajniji su žetveni ostaci [3], pri čemu je kukuruz najznačajnija i najzastupljenija biljna vrsta u Srbiji i APV.

Martinov i dr. [4] navode da oklasak kukuruza ima najveći energetski potencijal žetvenih ostataka u APV, i to na malim i srednjim farmama. Održivi potencijal oklaska je $15.000 \mathrm{t}$ za velike i $1.200 .000 \mathrm{t}$ za male i srednje farme [5,6]. Sagorevanje oklaska u ruralnim domaćinstvima je vrlo zastupljeno zbog dostupnosi, niske cene i niskog sadržaja vlage [3]. Najveći nedostatak predstavlja to što se za sagorevanje koriste jednostavni i neodgovarajući generatori toplote sa niskim stepenom korisnosti i visokim emisijama zagađujućih materija [7].

Gornja toplotna moć oklaska je od $18,3 \mathrm{MJ} \mathrm{kg}^{-1}$ do $18,8 \mathrm{MJ} \mathrm{kg}^{-1}$, a sadržaj pepela je niži od ostale poljoprivredne biomase i iznosi 1,36\% [8]. Sadržaj vlage oklaska kukuruza, nakon sušenja i krunjenja, dostigne vrednost od 10 do $12 \%$ oko $2 \%$ niži nego kod zrna [9]. Nasipna gustina oklaska ima vrednost oko $164 \mathrm{~kg} \mathrm{~m}^{-3}$ [10]. U pogledu toplotne moći, sadržaja vlage i pepela, oklasak kukuruza predstavlja pogodnije gorivo za sagorevanje od drugih žetvenih ostataka.

\section{NAPOMENA:}

Ovaj rad proistekao je iz master rada čiji mentor je bio dr Đorđe Đatkov, vanr. prof.
Nedostatak je niska nasipna gustina, pa je time manje pogodan za skladištenje i transport. Da se poveća nasipna gustina, potrebno je da se samelje ili peletira (briketira). Takve forme bi omogućile homogeniju strukturu, veću energetsku gustinu $i$ korišćenje $u$ naprednijim generatorima toplote $s$ višim stepenima korisnosti i nižim emisijama zagađujućih materija.

Cilj rada bio je da se istraži održivost (zaštita životne sredine, ekonomska i socijalna) korišćenja oklaska kukuruza kao goriva za generisanje toplotne energije $\mathrm{u}$ malim generatorima toplote $\mathrm{u}$ ruralnim oblastima. Pri tome, razmotrena je forma celog, drobljenog i peleta.

\section{MATERIJALI I METODE}

\subsection{Materijali}

\subsubsection{Oklasak kukuruza}

Oklasak kukuruza uzorkovan je u pogonu proizvođača peleta i mlevenog oklaska Fer Komerc DOO iz Slankamena. Sadržaj vlage oklaska iznosio je 8,45\%, sadržaj pepela $1,13 \%$, a donja toplotna moć na bazi suve mase $17,21 \mathrm{MJ} \mathrm{kg}^{-1}$. Nasipne gustine celog oklaska, drobljenog i peleta su $200 \mathrm{~kg} \mathrm{~m}^{-3}, 300 \mathrm{~kg} \mathrm{~m}^{-3} \mathrm{i} 700 \mathrm{~kg} \mathrm{~m}^{-3}$, respektivno.

\subsubsection{Scenariji korišćenja oklaska kukuruza kao goriva za ocenu održivosti}

Analizirana su tri scenarija korišćenja oklaska kukuruza kao goriva za sagorevanje u malim generatorima toplote i generisanje toplotne energije. Svaki od navedenih scenarija podrazumeva različitu formu oklaska, a time i različite zahteve za preradom, transportom i skladištenjem, kao i različitim tipom generatora toplote. Scenariji su:

1.Ceo oklasak. Ceo oklasak nalazi se u ekonomskom dvorištu domaćinstava ruralnih oblasti, uz moguće dopremanje dodatne količine oklaska od drugih izvora. Oklasak kukuruza se ne prerađuje, već se samo skladišti pre sagorevanja. Generator toplote za sagorevanje je veoma jednostavan, sa ručnim loženjem i bez kontrole procesa sagorevanja.

2.Drobljeni oklasak. Ova forma omogućava automatizaciju procesa loženja generatora toplote. Scenario podrazumeva da se oklasak doprema od različitih izvora, a zatim drobi i koristi kao gorivo za sopstvene potrebe ili se njime trguje. Ako se ovim gorivom eventualno trguje, dodatno se razmatra njegovo pakovanje, transport i skladištenje. Generator toplote je automatizovan, s upravljanjem količine vazduha za sagorevanje. 
3.Peleti oklaska. Ovaj scenario je sličan drugom, ali se oklasak nakon drobljenja dodatno melje i peletira. Peletiranjem se oklasku značajno povećava nasipna gustina, pa je gorivo pogodnije za transport na veće udaljenosti. Generator toplote je i u ovom scenariju automatizovan, s upravljanjem količinom vazduha za sagorevanje.

\subsubsection{Podaci za sprovođenje ocene održivosti}

Za potrebe transporta razmotrena opcija za scenario I je da masa koja se transportuje iznosi $14 \mathrm{t}$ [11], a transportno rastojanje iznosi $100 \mathrm{~km}$. U scenariju II i III masa koja se transportuje je $20 \mathrm{t}$ [11], a rastojanje prilikom dopremanja celog oklaska do proizvodnog pogona iznosi $80,84 \mathrm{~km}$ (prosečno rastojanje semenskih centara od proizvodnog pogona), dok u slučaju dopremanja gotovih proizvoda (drobljeni oklasak i pelet), razmotrena su rastojanja od $300 \mathrm{~km}$. Emisije za dizel gorivo iznose $93,9 \mathrm{gCO}_{2 \mathrm{ekv}} \mathrm{MJ}^{-1}$, a potrošnja goriva $\mathrm{za}$ transport $0,811 \mathrm{MJ} \mathrm{t}^{-1} \mathrm{~km}^{-1}$ [12].

Električna energija potrebna za drobljenje i peletiranje oklaska iznosi 20 i $80 \mathrm{kWh} \mathrm{tVM}^{-1}$ (VM - vlažna masa), respektivno [13]. Emisioni faktor za elektroenergetski sistem u RS iznosi 275,3 $\mathrm{gCO}_{2 \mathrm{ekv}} \mathrm{MJ}^{-1}$ [14], a efikasnost energetske transformacije 0,535 [15].

Za drobljeni oklasak razmotrena je opcija pakovanja u džambo vreće od polipropilenske tkanine (PP) u koje stane oko $300 \mathrm{~kg}$ drobljenog oklaska, dok za pelet razmotreno je pakovanje u džakove od LDPE (low density polyethylene) od $15 \mathrm{~kg}$. Izmerena je masa džambo vreće i džaka i iznose $1,5 \mathrm{~kg}$ i $38,15 \mathrm{~g}$, respektivno. Energija potrebna za PP iznosi $83 \mathrm{MJ} \mathrm{kg}^{-1}$, a emisije $1,95 \mathrm{gCO}_{2 \mathrm{ekv}} \mathrm{kg}^{-1}$, dok za LDPE iznose $73,1 \mathrm{MJ} \mathrm{kg}^{-1} \mathrm{i}$ $2,06 \mathrm{gCO}_{2 \mathrm{ekv}} \mathrm{kg}^{-1}[16,17]$.

Pošto se u scenariju II i III koriste automatizovani generatori toplote, potrebno je da se napajaju električnom energijom za pogon uređaja za doziranje goriva i vazduha za sagorevanje. Električna energija potrebna da se sagori jedna tona peleta na bazi suve mase u generatoru toplote termičke snage $48 \mathrm{~kW}$ iznosi 24,63 kWh [18]. Korišćeni godišnji stepen korisnosti generatora toplote u scenariju I iznosi 65\%, a za scenario II i III 80\% [19].

Emisije gasova koje doprinose efektu staklene bašte (GHG) koje nastanu tokom sagorevanja oklaska kukuruza, osim $\mathrm{CO}_{2}$, uzete su u obzir u ovom proračunu i za oklasak kukuruza iznose $0,24 \mathrm{gCO}_{2 \mathrm{ekv}} \mathrm{MJ}^{-1}$ [12].

Za potrebe analize ekonomske održivosti razmotreno je grejanje stambene kuće grejne površine $100 \mathrm{~m}^{2}$, godišnjih energetskih potreba $10 \mathrm{MWh}$. Gorivo sa kojim se porede tri forme oklaska kukuruza je prirodni gas iz distributivne mreže donje toplotne moći $33,34 \mathrm{MJ} \mathrm{Sm}^{-3}$ i cene $30,20 \mathrm{c€} \mathrm{Sm}^{-3}$ [18,19]. Donja toplotna moć oklaska je izmerena i iznosi $17,19 \mathrm{MJ} \mathrm{kg}^{-1}$, dok cene za ceo, drobljeni i pelet oklaska iznose 42, 100 i $140 € \mathrm{t}^{-1}$, respektivno [11].

Snaga i godišnji stepen korisnosti gasnog kotla je $15 \mathrm{~kW} \mathrm{i}$ $85 \%$, a kotla za poljoprivrednu biomasu $29 \mathrm{~kW}$ i $80 \%$ [19,21]. Radni vek gasnog kotla je 20 godina, dok kotla za poljoprivrednu biomasu 10-15 godina. Investicioni i pogonski troškovi gasnog kotla iznose: cena $605 €$, montaža i probni rad $200 €$, održavanje $150 €$ i materijalni troškovi $100 €[19,20]$. Za kotao za poljoprivrednu biomasu troškovi iznose: cena $2.100 €$, montaža i probni rad $200 €$, transport $121 €$, održavanje i materijalni troškovi su jednaki nuli [18].

Za izvore finansiranja razmotrene su tri opcije (sopstvena sredstva, $50 \%$ i $100 \%$ iz kredita). Kamatna stopa iznosi $15,79 \%$ [21], a perioda otplate kredita od 3, 5 i 7 godina.

\subsection{Metode}

\subsubsection{Sprovođenje energetskog bilansa}

Prema dokumentu Verein Deutscher Ingenieure - VDI 4600, kumulativna potreba za energijom (Kumulierter Energieaufwand - KEA) je ukupna primarna energija potrebna za proizvodnju, upotrebu i zbrinjavanje materijalnih i nematerijalnih dobara [22].

Pored ukupne uložene energije $\mathrm{KEA}_{\mathrm{U}}$, sprovedene su i analize energetskih pokazatelja: odnos energije (Energy Ratio - ER, u $\mathrm{MJ}_{\mathrm{p}} / \mathrm{MJ}_{\mathrm{f}}$ ), neto dobijena energija (Net Energy Gain - NEG, u $\mathrm{MJ} \mathrm{t}^{-1}$ ) i indeks energetske efikasnosti (Energy efficiency index $-\eta_{E}$ ). ER definiše se kao odnos energetske vrednosti izlaza (proizvoda) i ukupne uložene energije u proizvodnju tog proizvoda, $\mathrm{tj}$. ovaj pokazatelj govori o tome koji udeo ulazne energije se transformiše $u$ korisnu izlaznu energiju. Ovaj indeks omogućava poznavanje uticaja inputa izraženih u energetskim jedinicama $\mathrm{u}$ dobijanju proizvoda (biomase) [23]. NEG pokazuje čistu energetsku dobit, odnosno razliku između energije proizvoda i uložene energije u njegovu proizvodnju.

\subsubsection{Sprovođenje bilansa emisija gasova s efektom staklene bašte}

Bilansi emisija GHG, za sva tri navedena scenarija, sprovedeni su u skladu sa RED (Renewable Energy Directive) metodom [24].

\subsubsection{Ocenjivanje održivosti aspekta životne sredine}

Uštede emisija GHG izračunavaju se kao količnik razlike emisija fosilnog komparatora (FK) i ukupno generisanih emisija, s emisija fosilnog komparatora. FK za biomasu koja se koristi za potrebe grejanja iznosi $80 \mathrm{gCO}_{2 \mathrm{ekv}} \mathrm{MJ}^{-1}$ [24]. Ušteda emisije opisuje da li je korišćenje određene vrste goriva održivo, poređenjem sa kriterijumom održivosti koji iznose $70 \%$ od 2021., odnosno $80 \%$ od 2026. godine [24].

\subsubsection{Ocenjivanje ekonomskog aspekta održivosti}

Ocena ekonomske opravdanosti ulaganja sprovedena je korišćenjem programskog alata BiomasaPro [19], u postojećim varijantama za ocenu rekonstrukcije i izgradnje.

\subsubsection{Ocenjivanje socijalnog aspekta održivosti}

Ocenjivanje socijalnog aspekta održivosti sprovedeno je za tri navedena scenarija. Ocenjivanje je sprovedeno na osnovu dostupnosti i prihvaćenosti navedene tri forme oklaska. Korišćeni su stavovi i principi prethodnih istraživanja o korišćenju oklaska kukuruza [2,3,9].

\section{REZULTATI I DISKUSIJA}

\subsection{Energetski bilans}

Na grafiku 1 prikazani su rezultati energetskog bilansa za sva tri scenarija. Vrednost ukupno uložene energije je najniža za ceo oklasak, a najviša za pelet od oklaska kukuruza. Energija uložena za transport predstavlja 
značajan udeo u energetskom bilansu za tri forme goriva. Za ceo oklasak predstavlja celokupnu uloženu energiju.

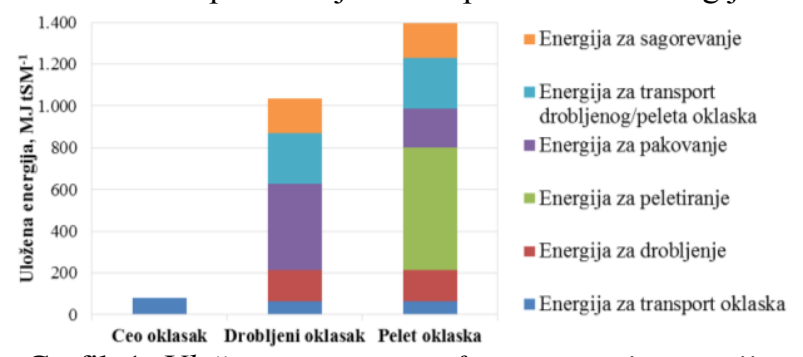

Grafik 1. Uložena energija po fazama za tri scenarija

$\mathrm{U}$ tabeli 1 prikazane su vrednosti energetskih pokazatelja za tri scenarija. Ukupna uložena energija $\left(K_{E} A_{U}\right)$ ima najnižu vrednost za ceo oklasak, a najvišu za pelet i iznose oko 81 i $1.395 \mathrm{MJ} \mathrm{t}^{-1}$ respektivno. Odnos uložene energije i energije dobijenog goriva (ER) ima takođe najvišu vrednost za ceo oklasak, pa zatim za drobljeni i pelet.

Vrednost neto dobijene energije (NEG) je niža za višu vrednost $\mathrm{KEA}_{\mathrm{U}}$. Vrednost indeksa energetske efikasnosti $\left(\eta_{\mathrm{E}}\right)$ za sva tri scenarija je visok i prelazi $90 \%$.

Tabela 1. Uporedni prikaz energetskih pokazatelja

\begin{tabular}{lcccc}
\hline Stavke & \multirow{2}{*}{ Jedinica } & $\begin{array}{c}\text { Ceo } \\
\text { oklasak }\end{array}$ & $\begin{array}{c}\text { Drobljeni } \\
\text { oklasak }\end{array}$ & $\begin{array}{c}\text { Pelet } \\
\text { oklaska }\end{array}$ \\
\hline $\mathrm{KEA}_{\mathrm{U}}$ & $\mathrm{MJ} \mathrm{tSM}^{-1}$ & 81,1 & $1.036,3$ & $1.395,2$ \\
$\mathrm{ER}$ & $\mathrm{MJ}_{\mathrm{p}} / \mathrm{MJ}_{\mathrm{f}}$ & 212,2 & 16,6 & 12,3 \\
$\mathrm{NEG}$ & $\mathrm{MJ}$ tSM & $17.126,9$ & $16.171,7$ & $15.812,8$ \\
$\eta_{\mathrm{E}}$ & $\%$ & 99,5 & 93,9 & 91,9 \\
\hline
\end{tabular}

\subsection{Bilans emisija gasova s efektom staklene bašte}

$\mathrm{Na}$ grafiku 2 dat je prikaz doprinosa emisija GHG u pojedinačnim fazama za tri scenarija. U scenariju za ceo oklasak, emisije iz transporta imaju najveći udeo, dok u scenariju za drobljeni oklasak značajan udeo emisija proizilaze iz drobljenja, transporta i rada kotla.

Kod scenarija za pelet oklaska, faza peletiranja je dominanta $u$ odnosu na ostale faze $u$ doprinosu emisija. Ukupne emisije za ceo, drobljeni i pelet oklaska iznose $0,7,5,4$ i $10,1 \mathrm{gCO}_{2 \mathrm{ekv}} \mathrm{MJ}^{-1}$.

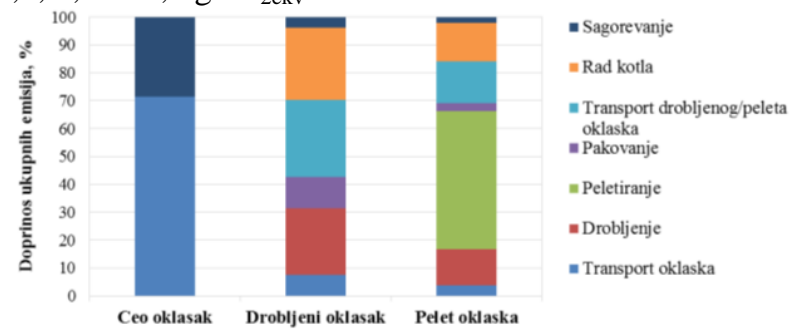

Grafik 2. Doprinos faza u ukupnom bilansu emisija $G H G$

\subsection{Ocena održivosti aspekta životne sredine}

Na grafiku 3 prikazane su ostvarene uštede u emisijama i kriterijume za održivost. Sva tri scenarija ispunjavaju kriterijume održivosti za oba perioda.

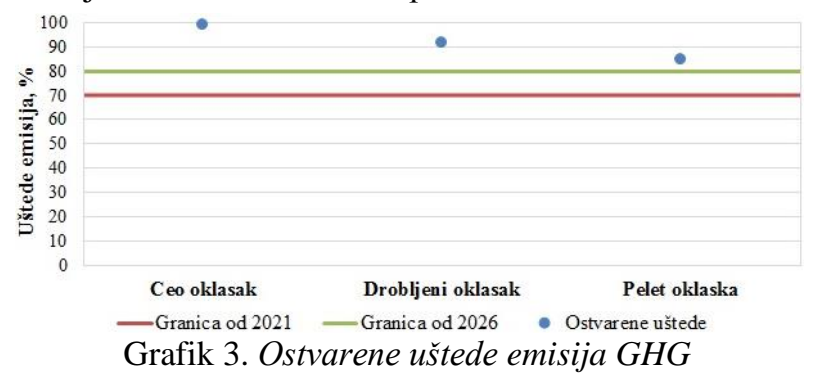

\subsection{Ocena ekonomskog aspekta održivosti}

Sva tri scenarija su ekonomski opravdana za varijantu izgradnje, tj. ulaganje u generator toplote na sve tri forme oklaska je isplativije nego na prirodni gas.

Za varijantu rekonstrukcije, ulaganje u generator toplote za ceo oklasak nije opravdano kada je radni vek 10 godina i kreditno zaduženje za celokupan iznos investicije. Za drobljeni oklasak ulaganja su opravdana samo u slučaju kada je radni vek kotla 15 godina i ako se celokupna investicija finansira iz sopstvenih sredstava, odnosno ako se $50 \%$ investicije finansira iz kredita sa periodom otplate 3 godine. Za pelet ulaganje u zamenu nije opravdano bez obzira na izvor finansiranja i vek trajanja opreme.

\subsection{Ocena socijalnog aspekta održivosti}

Ceo oklasak je široko dostupan u ruralnim oblastima, jer potiče sa vlastitih imanja potrošača ili se dobavlja iz neposredne blizine. Zbog toga je i njegovo korišćenje opšteprihvaćeno, kao i zbog niske. Nedostatak je njegova primena u jednostavnim generatorima toplote sa niskim stepenim korisnosti i visokim emisijama zagađujućih materija, što značajno utiče na životnu sredinu.

Drobljenjem celog oklaska postiže se neznatno viša vrednost nasipne gustine (oko $300 \mathrm{~kg} \mathrm{~m}^{-3}$ ), pa karakteristike za transport nisu značajno unapređene, a time ni uticaj na životnu sredinu usled dopremanje do udaljenih potrošaća. Ipak, omogućena je upotreba naprednijeg generatora toplote, koja omogućuje i komfor za korisnika.

Pelet je pogodna forma za korišćenje $u$ malim generatorima toplote najnaprednijih karakteristika. Dodatno, i zbog visoke vrednosti nasipne gustine (oko $700 \mathrm{~kg} \mathrm{~m}^{-3}$ ), pogodan je za transport na veće udaljenosti i korišćenje u prigradskim naseljima. Nedostatak je visoka cena.

\section{ZAKLJUČCI}

Najniže energetske potrebe su za ceo oklasak, a najviše za pelet, zbog potrebnih dodatnih faza u lancu pripreme i korišćenja.

Vrednosti ukupnih emisija GHG najmože su za ceo oklasak $\left(0,7 \mathrm{gCO} 2_{\mathrm{ekv}} \mathrm{MJ}^{-1}\right)$, a najviše $\mathrm{za}$ pelet $\left(10,1 \mathrm{gCO}_{2 \mathrm{ekv}} \mathrm{MJ}^{-1}\right)$. Za sva tri scenarija značajan udeo emisija potiče iz faze transporta.

Ostvarene uštede emisija GHG za sva tri scenarija ispunjavaju definisane kriterijume održivosti. Najviše vrednosti ušteda ostvarene su za ceo oklasak, zatim drobljeni, a najniže za pelet.

Ceo oklasak, zbog niske cene od $41 € \mathrm{t}^{-1}$, ostvaruje najbolje pokazatelje ocene ekonomskog aspekta održivosti, za obe varijante rekonstrukcije i izgradnje. Radni vek opreme i način finansiranja parametri su koji najviše utiču na opravdanost ulaganja.

Glavni nedostatak celog i drobljenog oklaska sa stanovišta socijalne održivosti u poređenju sa peletom je što su manje pogodni za transport i skladištenje zbog niže vrednosti nasipne gustine. Prednosti drobljenog oklaska i peleta su u tome što se mogu koristiti u generatorima toplote s automatskim loženjem, što je veći komfor za korisnika, ali ipak su to dve forme goriva sa višom cenom. 
Prema rezultatima istraživanja, korišćenje jedino forme celog oklaska je održivo u odnosu na ispitivane aspekte . U daljim istraživanjima potrebno je da se ispitaju i emisije zagađujućih materija iz procesa sagorevanja i utvrdi da li su one ispod definisanih graničnih vrednosti. Time bi održivost aspekta životne sredine $u$ potpunosti bila razmotrena.

\section{LITERATURA}

[1] Anonim, Nacionalni akcioni plan za obnovljive izvore energije Republike Srbije ( $u$ skladu sa obrascem predviđanom Direktivom 2008/29/E3 - Odluka 2009/548/EZ). Ministarstvo energetike, razvoja i zaštite životne sredine, Beograd, 2013.

[2] M. Martinov, M. Višković, Sanja Bojić, B. Dumnić, M. Golub, J. Krstić, Studija prostornog razmeštaja namenskih javnih skladišta agrarne biomase na teritoriji AP Vojvodine. Fakultet tehničkih nauka, Novi Sad, 2016.

[3] M. Martinov, M. Golub, M. Višković, Đ, Đatkov, J. Krstić, Studija ubiranja, skladištenja i prerade kukuruzovine za korišćenje kao energenta i sirovine za biogoriva na teritoriji AP Vojvodine. Fakultet tehničkih nauka, Novi Sad, 2016.

[4] M. Martinov i dr, Mogućnosti kombinovane proizvodnje električne $i$ toplotne energije iz biomase $u$ AP Vojvodini. Fakultet tehničkih nauka, Novi Sad, 2008.

[5] M. Ilić, (ed.), Energetski potencijal i karakteristike ostataka biomase i tehnologije za njenu pripremu $i$ energetsko iskorišćenje u Srbiji. Institut Vinča, Beograd, 2003.

[6] M. Martinov i M. Tešić,“Cereal/soybean straw and other crop residues utilization as fin Serbia-status and prospects" in Cereals straw and agricultural residues for bioenergy in European Union New Member States and Candidate Countries, N. Scarlat, J.F. Dallemand, M. Martinov, European Commission, Joint Research Centre, Institute for Environment and Sustainability, Novi Sad, Serbia, 2008, 2-3 October 2007, Book of Proceedings, 45-56.

[7] M. Martinov, M. Tešić, M. Brkić. 2006. „Efficiency and Emission of Solid Biomass Combustion Facilities in Serbia - Status and Needed Measures for Improvement", Thermal Science, vol. 10(4), pp. 189194, 2006.

[8] J.M. Ebeling i B.M. Jenkins, „Physical and chemical properties of biomass fuels“, Trans. ASAE, vol. 28(3), pp. 898-902, 1985.

[9] M. Martinov, B. Veselinov, S. Bojić, Đ. Đatkov, „Investigation of maize cobs crushing - Preparation for use as a fuel“", Thermal Science, vol. 15(1), pp. 235-243, 2011.

[10] N. Kaliyan i R.V. Morey, ,Densification characteristics of corn cobs“, Fuel Processing Technology, vol. 91(5), pp. 559-565, 2010

[11] Anonim, FER KOMERC DOO, direktor Ljepoja Vlado, lični kontakt (April 2019).

[12] J. Giuntoli, A. Agostini, R. Edwards, L. Marelli, Solid and Gaseous Bioenergy Pathways: Input Values and GHG Emissions, Publications Office of the European Union, Luxembourg, 2015.
[13] M.T. Miranda, F.J. Sepúlveda, J.I. Arranz, I. Montero, C.V. Rojas, „Analysis of pelletizing from corn cob waste", Journal of Environmental Management, vol. 228, pp. 303-311, 2018.

[14] Anonim, Baza podataka BioGrace, 2015. (https://www.biograce.net/app/webroot/biograce2/content/ghgcalcul ationtool electricityheatingcooling/overview) (pristupljeno juna 2019.)

[15] Službenom glasniku Republike Srbije, Odluka o utvrđivanju Energetskog bilansa Republike Srbije za 2019. godinu. Službenom glasniku Republike Srbije 105/2018, 2018.

[16] A. Thiriez i T. Gutowski, An Environmental Analysis of Injection Molding, In Proc. 2006 IEEE International Symposium on Electronics and the Environment, pp. 195-200. Scottsdale, AZ, USA, 8-11 May, 2006.

[17] Anonim, Winnipeg sewage treatment program. Appendix 7: $\mathrm{CO}_{2}$ emission factors database, Winnipeg, Canada, 2011.

(https://www.winnipeg.ca/finance/findata/matmgt/documents/2012/ 682-2012/682-2012_Appendix_H-

WSTP South End Plant Process Selection Report/Appendix\%20 7.pdf) (pristupljeno juna 2019.)

[18] Anonim, Termoplin DOO, Aleksandar Jugović dipl. inž. maš, lični kontakt (Maj 2019).

[19] M. Martinov, Program za ocenu ekonomskih pokazatelja za energetsku primenu biomase. Fakultet tehničkih nauka, Novi Sad, 2011.

[20] Anonim, 2019.

(http://cimgas.rs/goods_show.php?lg=sr\&id_goods=9412) (pristupljeno jula 2019.)

[21] Anonim, Erste kredita za energetsku efikasnost, 2019. (https://www.erstebank.rs/sr/Stanovnistvo/Krediti/kredit-zaenergetsku-efikasnost-iz-ebrd-linije) (pristupljeno jula 2019.)

[22] Verein Deutscher Ingenieure, VDI 4600: Kumulierter Energieaufwand: Begriffe, Definitionen,

Berechnungs-methoden. Düsseldorp, Deutschland, 1997.

[23] J. Ortiz-Cañavate i J.L. Hernanz, ,Energy Analysis and Savings", in Hadbook of Agricultural Engineering, Volume V, Energy \& Biomass Engineering, ed. O. Kitani, T. R.M. Jungbluth, Peart, A. Ramdani, ch. 2, pp. 13-42. CIGR, ASAE, SAD, 1999.

[24] European Commission, Directive (EU) 2018/2001 of the European Parliament and of the Council of 11 December 2018 on the promotion of the use of energy from renewable sources (recast) (Text with EEA relevance). Official Journal of the European Union, $\mathrm{L}$ 328/82, 2018.

\section{Kratka biografija:}

Aleksandar Nesterović rođen je u Tesliću 1995. god. Osnovne akademske studije na Fakultetu tehničkih nauka u Novom Sadu upisuje 2014., a master akademske studije 2018. godine na studijskom programu Čiste energetske tehnologije. kontakt: aco19nesterovic@yahoo.com

Đorđe Đatkov rođen je u Senti 1982. Doktorirao je na Fakultetu tehničkih nauka 2013. god., a od 2019. je u zvanju vanredni profesor. Oblast interesovanja je biomasa za energiju.

Miodrag Višković rođen je u Senti 1987. Od 2016. godine je u zvanju asistenta na Fakultetu tehničkih nauka. Oblast interesovanja je biomasa za energiju. 